Louisiana State University

LSU Digital Commons

Faculty Publications

Department of Chemistry

$4-1-2016$

\title{
Laser ablation sample transfer for localized LC-MS/MS proteomic analysis of tissue
}

Fabrizio Donnarumma

Louisiana State University

Kermit K. Murray

Louisiana State University

Follow this and additional works at: https://digitalcommons.Isu.edu/chemistry_pubs

\section{Recommended Citation}

Donnarumma, F., \& Murray, K. (2016). Laser ablation sample transfer for localized LC-MS/MS proteomic analysis of tissue. Journal of Mass Spectrometry, 51 (4), 261-268. https://doi.org/10.1002/jms.3744

This Article is brought to you for free and open access by the Department of Chemistry at LSU Digital Commons. It has been accepted for inclusion in Faculty Publications by an authorized administrator of LSU Digital Commons.

For more information, please contact ir@lsu.edu. 


\section{Laser Ablation Sample Transfer for Localized LC- MS/MS Proteomic Analysis of Tissue}

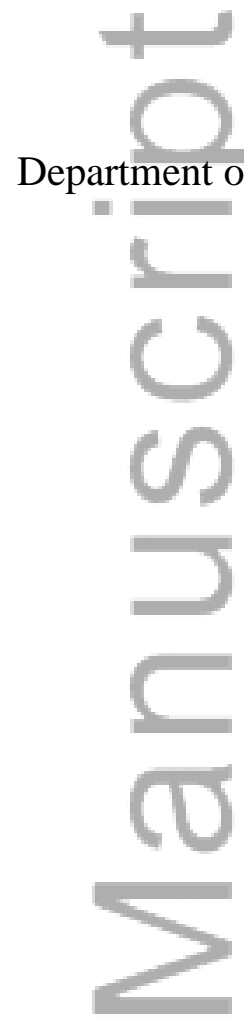

*Corresponding Author and reprint requests:

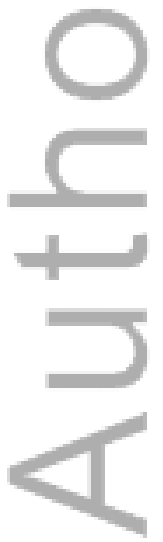

\author{
Fabrizio Donnarumma, Kermit K. Murray*
}


Fax: +1 (225) 5783458

E-mail: kkmurray@1su.edu

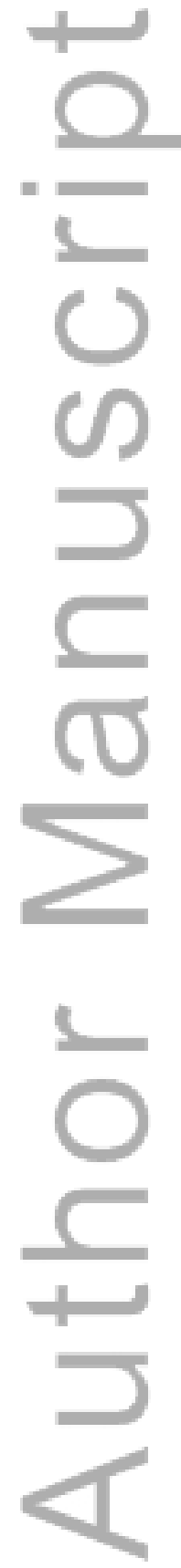




\begin{abstract}
We have developed a mid-infrared laser ablation sampling technique for nanoLC-MS/MS proteomic profiling of discrete regions from biological samples. Laser ablation performed in transmission geometry was used to transfer material from $50 \mu \mathrm{m}$ thick tissue sections mounted on a glass microscope slide to a capturing solvent. Captured samples were processed using filter aided sample preparation and enzymatically digested to produce tryptic peptides for data dependent analysis with an ion trap mass spectrometer. Comparison with UV laser capture microdissection from neighboring regions on the same tissue section revealed that infrared laser ablation transfer has higher reproducibility between samples from different consecutive sections. Both techniques allowed for proteomics investigation of different organelles without the addition of surfactants.
\end{abstract}

Keywords: IR laser ablation, UV laser capture microdissection, Proteomics, LC-MS/MS, Localized Sampling

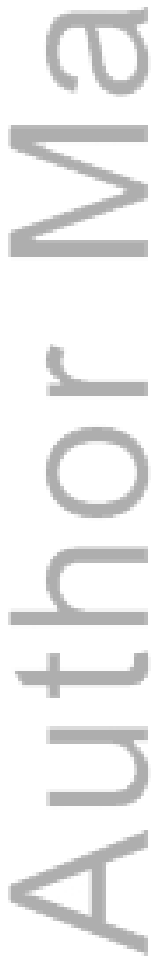




\section{Introduction}

Over the past decade, high throughput liquid chromatography mass spectrometry has become an indispensable tool for the investigation of many types of biomolecule classes in complex samples. ${ }^{[1-3]}$ Among the different "-omics" techniques, proteomics has the ability to discover highly specific structural and functional differences at the cellular level. Large scale high throughput proteomics experiments can be performed on different samples, ranging from cell cultures ${ }^{[4]}$ to tissue. ${ }^{[5]}$ In particular, mass spectrometry has shown great potential as a tool to increase the information obtained from tissue sections that are routinely prepared for histological analysis. Mass spectrometry can be conducted on tissue extracts as well as through approaches such as MALDI imaging ${ }^{[6]}$ and mass cytometry imaging. ${ }^{[7]}$ Analyzing tissue extracts has the advantage of providing identification of a large number of proteins. At the same time, any spatial localization and cell type information is lost. Mass spectrometry imaging techniques can preserve spatial information, but they are not capable of providing a comprehensive picture of medium and low abundant proteins that can be detected using liquid chromatography coupled with mass spectrometry (LC-MS). Extraction of spatially localized regions of interest from tissue samples is a strategy that can help bridge the gap between the two approaches.

There are several methods to separate tissue components in complex biological samples ${ }^{[8]}$ and some have been used for LC-MS analysis such as fluorescence activated cell sorting (FACS). ${ }^{[9]}$ However, most of these techniques cannot handle cells from solid tissue samples while preserving localization information. Laser capture microdissection (LCM) is a technique in which a laser is used to cut and separate a region of interest from a tissue section. The first instrument was developed by Emmert-Buck and co-workers in 1996. ${ }^{[10]}$ This approach uses a thin thêrmoplastic film that covers the section. A near-IR laser is focused onto the film, which melts and is fused with the cells and tissue material. The film is detached together with the isolated region. A second variant of LCM was developed by Schütze and Lahr ${ }^{[11]}$ in 1998. In this case, a UV laser at $355 \mathrm{~nm}$ is directed to the sample in transmission geometry allowing selective 
cutting of the region of interest, which can then be detached with the same laser by applying pulses at lower energy. The material is catapulted toward a cap containing a capturing solvent or an adhesive substrate. In both cases, coupling the sampling system with microscopy enables the use multiple approaches to determine which area to select. In a recent work, Vandewoestyne and co-workers ${ }^{[12]}$ compared the two techniques with regard to genomic analysis of the collected material and concluded that the UV instrumentation is a faster and more precise approach. UV LCM instruments have been used extensively for LC-MS/MS and other mass spectrometry proteomics investigations. ${ }^{[13]}$ For example, Stingl and co-workers ${ }^{[14]}$ analyzed LCM processed biopsies with high resolution LC-MS and were able to study the proteomes of different cell populations.

Chung and Shen ${ }^{[15]}$ recently reviewed the use UV LCM in neurodegeneration research, highlighting the advantages the technique can bring to proteomic LC-MS/MS. At the same time, they reported some of the limitations of this technology, which are the high cost of the instrumentation as well as expensive consumables. Moreover, other factors such as tissue dehydration, operator training, and sample-to-sample parameter tuning can affect the quality of the biological material. In addition, Cheng and co-workers ${ }^{[16]}$ reported the risks of possible crosscontamination of the collected samples with neighboring regions as well as thickness limitation.

Localized extraction of protein material can be achieved by using in-situ liquid extraction approaches such as liquid extraction surface analysis (LESA) ${ }^{[17]}$ which is based on the formation of a liquid microjunction between the surface of interest and a solvent delivery capillary. Solvent can be is continuously delivered to the tissue and aspirated back into a second capillary. This approach has been used both for extraction of intact proteins for bottom-up and top-down mass spectrometry $^{[18]}$ as well as for extraction of tryptic peptides from in-situ tryptic digestion of the protein material. ${ }^{[19]}$ Sampling precision is limited by the size of the microjunction, which can vary from 0.5 to $1.6 \mathrm{~mm} .^{[20,21]}$ Laskin and co-workers ${ }^{[22]}$ introduced an approach capable of performing a liquid junction with a spatial resolution of about $10 \mu \mathrm{m}$ by using a delivering silica capillary and a second capillary directly coupled to the ESI interface of a mass spectrometer. 
This approach has been successfully employed for imaging mass spectrometry experiments of small molecules but no data about its capabilities with regards to extraction of high molecular weights compounds has been reported so far.

A different approach to sampling a localized area on a tissue section is offered by laser ablation. By consecutive spot to spot irradiation of the entire area of interest with a focused laser beam, it is possible to remove the totality of the material with the additional advantage of extracting the biomolecule components. Laser ablation can be achieved with UV LCM systems by operating them in laser ablation dissection mode (also termed dot scanning dissection). This operation mode made it possible for Lorenz and co-workers ${ }^{[23]}$ to couple a UV LCM instrument to a mass spectrometer in order to create a mass spectrometry imaging system.

In our previous work, we demonstrated that IR lasers at $3 \mu \mathrm{m}$ can be used to transfer peptides and proteins from tissue sections on microscope slides in reflection ${ }^{[24]}$ or transmission ${ }^{[25]}$ geometry. The material can be captured on a second microscope slide for MALDI imaging analysis, ${ }^{[25,26]}$ or transferred to a solvent stream for direct LC-MS ${ }^{[27]}$ or capillary electrophoresis (CE) $\mathrm{MS}^{[28]}$ analysis. Recently, Kwiatkowski and co-workers ${ }^{[29]}$ reported a method for extracting proteins tissue using a picosecond IR laser and capturing the ablated material with a cryo-trap. IR laser irradiation can transfer large biomolecules without fragmentation or introduction of undesired modifications. This property of IR lasers can be exploited to transfer material from a discrete region of interest on thin tissue sections. IR laser ablation methods have a lower lateral resolution by approximately an order of magnitude compared to UV due to the longer wavelength and diffraction limited optics. However, high numerical optics can reduce the spot size to tens of micrometer in diameter, approaching the size of mammalian cells. ${ }^{[30,31]}$

In this work, we demonstrate IR laser ablation sample transfer (IR LAST) for extraction of biological material from rat brain tissue sections mounted on a microscope slide by irradiation in transmission geometry for capture in a solvent located below the area of interest. We provide a comparison with UV LCM operated in dot scanning mode under identical conditions and 
demonstrate that the captured material can be further processed for high throughput LC-MS/MS proteomic analysis.

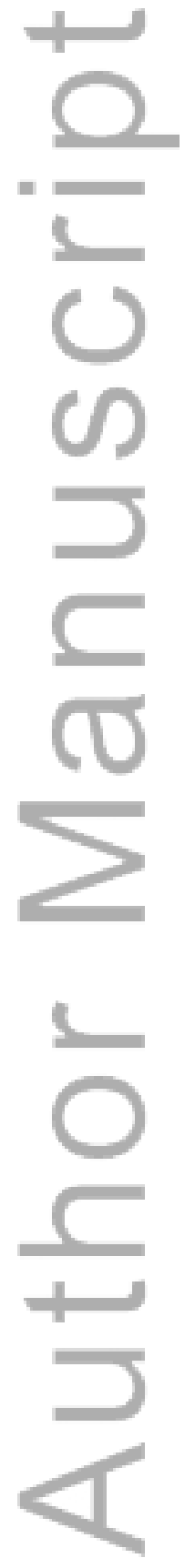




\section{Material and methods}

\subsection{Chemicals and biological samples}

Trimethamine (tris) base was obtained from BioRad (Hercules, CA, USA). DL-Dithiothreitol (DTT, 98\%), iodoacetamide (IAA, Bioultra, 99\%) and ammonium bicarbonate (ABC, BioUltra, 99.5\%) were obtained from Sigma-Aldrich (St. Louis, MO, USA). Formic acid (FA, 98\%, LCMS Ultra grade), acetonitrile (99.9\%, LC-MS grade) and water (Optima LC/MS grade) were obtained from Fisher Scientific (Atlanta, GA, USA). Sequencing grade modified trypsin was purchased from Promega (Madison, WI, USA). Ultrapure water $(18 \mathrm{MJ} \mathrm{cm}$ ) was produced inhouse. Ultracetrifugation cartridges (10 kDa cut-off) were obtained from PALL (Port Washington, NY, USA). Glass microscope slides $(25 \times 75 \mathrm{~mm})$ were obtained by VWR (West Chester, PA, USA). A Bradford assay kit (Pierce Coomassie Plus) and bovine serum albumin (BSA) were obtained from Life Technologies (Grand Island, NY, USA).

Tris buffer was prepared at a concentration of $50 \mathrm{mM}$ and corrected to a $\mathrm{pH}$ of 8.5. ABC buffer was prepared at a concentration of $10 \mathrm{mM}$ and corrected to a $\mathrm{pH}$ of 7.4.

\subsection{Tissue samples}

Tissue samples were obtained from 4-6 week old breeding rats at the LSU School of Veterinary Medicine Division of Laboratory Animal Medicine (DLAM). The animals were sacrificed by $\mathrm{CO}_{2}$ (5 psi) exposure for 1 hour. Brain samples were collected, washed in $50 \mathrm{mM}$ ammonium bicarbonate buffer for 30 seconds, and frozen in liquid nitrogen within 30 minutes. Frozen samples were stored at $-80{ }^{\circ} \mathrm{C}$. Thin sections were prepared with a Leica CM1850 cryostat (Leica Microsystems, Wetzlar, Germany) directly from the frozen tissue. Optimal cutting temperature (OCT) solution was used to fix one side of the sample to the cryostat support. Particular care was taken to avoid any contact of the OCT solution with the exposed side of the tissue. Horizontal (transverse) rat brain sections were cut at a thickness of $50 \mu \mathrm{m}$, thaw-mounted on uncoated 
microscope slides, and stored at $-80{ }^{\circ} \mathrm{C}$. Two consecutive sections were mounted on each microscope slide.

\subsection{Laser Ablation Sample Transfer}

Laser ablation sampling was performed before laser capture microdissection. Tissue sections were dried under vacuum for 30 minutes prior to sampling. Microscope slides were mounted on a two-axis translation stage (M-433, Newport, Irvine, CA) operated using $50 \mathrm{~mm}$ actuators (LTA-HS, Newport) and a motion controller (ESP3000, Newport). The mid-IR laser system used for ablation has been described previously. ${ }^{[32]}$ Briefly, sample slides were irradiated in transmission geometry with a wavelength tunable pulsed IR optical parametric oscillator (IR Opolette, OPOTEK, Carlsbad, CA, USA). The beam was directed normal to the surface and focused with a $50 \mathrm{~mm}$ focal length lens. The laser pulse width was $5 \mathrm{~ns}$ and the repetition rate was $20 \mathrm{~Hz}$. The wavelength was set at $2.94 \mu \mathrm{m}$ to overlap with the $\mathrm{OH}$ stretch absorption and facilitate comparison with previous studies. ${ }^{[33]}$ Furthermore, we have found that the $\mathrm{OH}$ absorption at $3.0 \mu \mathrm{m}$ is more efficient than the $\mathrm{CH}$ absorption at $3.4 \mu \mathrm{m}$ even in nominally dehydrated samples. ${ }^{[34]}$ A $300 \mu \mathrm{L}$ PCR tube filled with $200 \mu \mathrm{L}$ of capture solvent was placed below the ablation spot and held close to the slide by moving a manually operated translation stage vertically. Experiments were conducted at a fluence of $30 \mathrm{~kJ} / \mathrm{m}^{2}$. The laser was attenuated internally using laser control software, and no external attenuation elements were used. A square raster pattern was used to ablate regions of the sample at a stage velocity of $1 \mathrm{~mm} / \mathrm{s}$. Upon completion of the ablation process, the tube was vortexed for 30 seconds and stored at $-20{ }^{\circ} \mathrm{C}$ until further processing. The tissue sections were then processed using the laser capture microdissection system.

\subsection{UV LCM laser ablation}

UV laser ablation experiments were conducted with a PALM Microbeam instrument (Zeiss, Thornwood, NY, USA) equipped with a nitrogen laser at $337 \mathrm{~nm}$ wavelength. The maximum output energy was $90 \mu \mathrm{J}$, the repetition rate was $100 \mathrm{~Hz}$, and the pulse width was $2 \mathrm{~ns}$. The 
maximum energy was selected for all experiments, which allowed detachment of tissue material with a laser spot diameter of $20 \mu \mathrm{m}$. Ablation was conducted in transmission mode over an area of $1.1 \times 1.2 \mathrm{~mm}$ adjacent to the IR ablated regions. Capture was performed on a $600 \mu \mathrm{L}$ centrifuge tube cap. A total of $40 \mu \mathrm{L}$ of capture solvent was added to the cap, which was then mounted face-down on the holder and moved above the laser ablation spot. Sampling was performed in dot scanning dissection mode. The ablation area was rastered with spots spaced at interval of 15 $\mu \mathrm{m}$. Upon completion of the ablation process, the cap was placed on a centrifuge tube and the sample was vortexed and briefly centrifuged at $1,000 \mathrm{~g}$ before storing at $-20{ }^{\circ} \mathrm{C}$. The tissue sections were then prepared for microscope imaging acquisition.

\subsection{Microscopy imaging}

Microscopy images were acquired with a fluorescence stereomicroscope (SteREO Lumar V12 , Zeiss) equipped with a $0.8 \times$ Neolumar $S$ objective and a high resolution digital camera (AxioCam HRc, Zeiss). Images were recorded in bright field mode and exported using Zen 2012 (Zeiss)

\subsection{Protein concentration estimation}

Protein concentration estimation was conducted with a Bradford colorimetric assay. Calibration curves were obtained in triplicate using bovine serum albumin (BSA) standards. For these measurements, samples from UV LCM and LAST were vacuum dried and reconstituted in $15 \mu \mathrm{L}$ of $\mathrm{ABC}$ buffer, which was added to $100 \mu \mathrm{L}$ of reagent solution. Analyses were performed in 96 well plates that were incubated for 15 minutes at room temperature before spectroscopic readings at $595 \mathrm{~nm}$.

\subsection{Filter aided sample processing}

Proteomic sample processing was performed based on the protocol of Wisniewski and coworkers $^{[35]}$ with a few modifications. Briefly, the UV LCM samples were added to $160 \mu \mathrm{L}$ of capture solvent (50 mM tris, $\mathrm{pH} 8.5$ ). Protein disulfide bonds reduction was achieved by adding 
DTT to each tube to a final concentration of $10 \mathrm{mM}$ and the samples were incubated at $80{ }^{\circ} \mathrm{C}$ for 45 minutes. After cooling at room temperature for 15 minutes, the samples were transferred to ultrafiltration cartridges with a molecular weight cut-off of $10 \mathrm{kDa}$ and centrifuged at $14,000 \mathrm{~g}$ for 20 minutes. Alkylation was performed by adding $100 \mu \mathrm{L}$ of a $20 \mathrm{mM}$ IAA solution to each unit followed by incubation in the dark for 30 minutes. After incubation, the samples were centrifuged again at $14,000 \mathrm{~g}$ for 10 minutes. Buffer exchanges and washing steps were performed together by adding $100 \mu \mathrm{L}$ of $\mathrm{ABC}$ buffer to each tube and centrifugation at $14,000 \mathrm{~g}$ for 10 minutes. This step was repeated twice, after which filter units were placed in clean tubes. Enzymatic digestion of the protein material was achieved using $50 \mu \mathrm{L}$ of ABC buffer and $1 \mu \mathrm{L}$ of a $50 \mathrm{ng} / \mu \mathrm{L}$ trypsin solution. Samples were incubated at $37^{\circ} \mathrm{C}$ overnight and shaken at 200 $\mathrm{rpm}$. After digestion, the filter units were centrifuged at $14,000 \mathrm{~g}$ for $10 \mathrm{~min}, 50 \mu \mathrm{L}$ of $\mathrm{ABC}$ buffer added, and centrifuged again. The filter units were removed and the tryptic mixtures were vacuum dried. The dried samples were stored at $-20{ }^{\circ} \mathrm{C}$ until analysis.

\subsection{Mass Spectrometry}

LC-MS/MS chromatograms were recorded using (Bruker Daltonics, Bremen, Germany) Amazon Speed ETD ion trap equipped with a Dionex Ultimate 3000 RSLC UPLC system (Dionex, Sunnyvale, California, USA). A CaptiveSpray ionization source (Bruker) was used to perform nano electrospray. Samples were resuspended in $60 \mu \mathrm{L}$ of 95:5, $\mathrm{H}_{2} \mathrm{O}$ : ACN with 0.1\% FA. A total of $20 \mu \mathrm{L}$ was injected in full loop mode and trapped on a $5 \mathrm{~mm}$ Acclaim PepMap100 trap column (C18, $5 \mu \mathrm{m}, 100 \AA$ A, $300 \mu \mathrm{m}$ i.d., Thermo Scientific) using an isocratic mixture of 95:5, $\mathrm{H}_{2} \mathrm{O}$ : ACN with $0.1 \%$ FA. Trapping was conducted for 10 minutes at a flow rate of $30 \mu \mathrm{L} / \mathrm{min}$ equal to 15 loop volumes. A gradient run was performed using a $150 \mathrm{~mm}$ Acclaim PepMap100 analytical column (C18, $3 \mu \mathrm{m}, 100 \AA, 75 \mu \mathrm{m}$ i.d.) using a gradient elution program with mixture A (95:5, $\mathrm{H}_{2} \mathrm{O}$ : ACN with 0.1\% FA) and $\mathrm{B}\left(20: 80, \mathrm{H}_{2} \mathrm{O}: \mathrm{ACN}\right.$ with $0.1 \%$ FA. After a 2 minute equilibration at $100 \% \mathrm{~A}$, the gradient was ramped linearly to $50 \% \mathrm{~B}$ over 90 minutes, then to $80 \%$ B over 15 minutes and finally to $100 \%$ B over 3 minutes. The column was washed at 100\% B for 10 minutes and the gradient was ramped to $100 \%$ A over 3 minutes. An additional 10 
minutes at $100 \%$ A were added for column re-equilibration. Each sample was injected once and a blank run was performed afterward to evaluate carry over effects.

\subsection{Data Analysis}

Raw data were processed with Data Analysis 4.1 (Bruker). Peak lists were created using an intensity threshold of 1,000 counts for the MS/MS spectra in the range 15-80 minutes. Database searches were conducted using SearchGUI ${ }^{[36]}$ (ver. 1.30.1) using 6 engines (X!Tandem ${ }^{[37]}$ MS$\mathrm{GF}+,{ }^{[38]} \mathrm{MS}$ Amanda, ${ }^{[39]}$ MyriMatch, ${ }^{[40]}$ Comet $^{[41]}$ and OMSSA $\left.{ }^{[42]}\right)$. Windows tolerances for MS and MS/MS were set to 0.5 and $1 \mathrm{Da}$ respectively. Carbamidomethylation of cysteine was selected as a fixed modification while methionine oxidation and acetylation of protein n-termini were selected as variable modifications. The maximum number of missed cleavages was set to 2 . The latest available version of SwissProt (release 2015/07) was selected as the database and search results were further analyzed with PeptideShaker ${ }^{[43]}$ (ver. 0.41.1) with a false discovery rate of 5\%. Protein IDs were used to retrieve localization information from UniProtKB (release 2015/07) ${ }^{[44]}$ Base peak chromatograms were rebuilt from the original raw dataset using MZmine $2^{[45]}$ (ver. 2.15) and plotted using KaleidaGraph (ver. 4.5, Synergy Software, Reading, PA, USA).

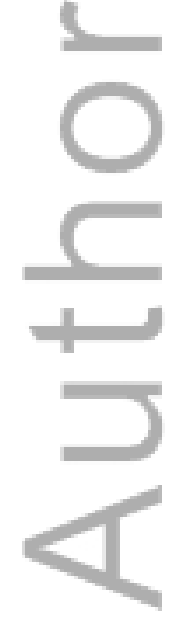




\section{Results and discussion}

Initial studies were performed to evaluate and optimize UV LCM and LAST for the transfer of biological material from $50 \mu \mathrm{m}$ thick tissue sections. The first parameter taken into consideration was the LCM laser energy and focus that were optimized with tissue samples. The LCM instrument has two cutting modes: laser cutting mode and laser ablation dissection. In laser cutting mode, the laser is continuously operated while the slide is moved with an $\mathrm{X}$-Y stage. Even using the highest repetition rate $(100 \mathrm{~Hz})$, laser cutting mode did not consistently detach all of the material in a selected area, often producing partial removal or leaving a dark trace about $20 \mu \mathrm{m}$ wide that was associated with sample charring. A more consistent ablation was achieved with laser ablation mode. In this mode, the laser is held in one position and the desired number of shots is directed to the sample, then the laser is moved to the next position, continuing until the desired area is irradiated. The highest material removal was achieved using 100 shots per position at $90 \mu \mathrm{J}$ per pulse, the maximum energy available. As shown in Figure 1, these parameters resulted in complete ablation of lines about $20 \mu \mathrm{m}$ wide. Therefore, LCM sampling was conducted in laser ablation mode with a spot to spot distance of $15 \mu \mathrm{m}$.

LAST was conducted using IR laser pulse energies ranging from 0.4 to $1.2 \mathrm{~mJ}$. The laser was continuously operated while the sample slide, mounted on an X-Y stage, was moved. Complete material ablation was achieved at $0.9 \mathrm{~mJ}$ energy, repetition rate of $20 \mathrm{~Hz}$, and a translation velocity of $1 \mathrm{~mm} / \mathrm{s}$. This combination resulted in complete ablation of lines about $200 \mu \mathrm{m}$ wide as shown in Figure 1. Finally, ablation of larger areas was achieved by moving the stage in a line raster pattern with a spacing of $100 \mu \mathrm{m}$ between each line to cover a $1 \times 1 \mathrm{~mm}$ area. Sampling via LAST was significantly faster than UV LCM sampling. At a stage translation velocity $(1 \mathrm{~mm} / \mathrm{s})$, LAST achieved complete ablation of the $\sim 1 \mathrm{~mm}^{2}$ sample area in 10 seconds whereas the LCM instrument required over one hour per sample. This higher sampling speed LAST may reduce sample degradation effects due to air exposure, such as oxidation. ${ }^{[46]}$ 
Whereas the volume of capture solvent allowed with the UV LCM instrument was limited to 40 $\mu \mathrm{L}$ by the size of the cap, the capture solvent volume for the IR ablation capture can be optimized in order to reduce the distance between the solvent surface and the tissue section. The rationale for the wavelength choice in the IR ablation experiment was the overlap of $3 \mu \mathrm{m}$ wavelength with the $\mathrm{OH}$ stretch vibrational absorption of water, which is present in high concentration in the tissue sections even after vacuum drying. However, if the IR laser pulse irradiates the surface of the capturing solvent, it can cause ablation of the solvent and possible contamination of the slide. A capture solvent volume of $200 \mu \mathrm{L}$ placed the solvent surface $5 \mathrm{~mm}$ below the tissue, which resulted in capture of protein material with no ablation of the solvent observed.

The following set of experiments was aimed at determining the protein recovery achievable with the two systems as well as to obtain an initial qualitative and quantitative comparison between the two techniques. Areas of $1.2 \times 1.1 \mathrm{~mm}$ were ablated on two consecutive $50 \mu \mathrm{m}$ tissue sections mounted on the same microscope slide, resulting in maximal removal of a $0.07 \mathrm{~mm}^{3}$ volume of material. Figure 2 shows bright field microscope images of ablated areas on a tissue section, corresponding to cerebellum, midbrain and striatum regions of the brain. The size of the ablated area allowed for sampling of similar regions for UV LCM and LAST. In all of the experiments, LAST was able to efficiently remove nearly all of the material from the selected area whereas UV LCM sampling was characterized by incomplete removal of the material. Additional UV LCM sampling of the areas that were not completely ablated removed little additional material. The expanded images on the right in Figure 2 show the ablation regions produced by the two methods. Whereas UV LCM is characterized by sharply defined borders, the LAST ablated areas display a slightly more irregular shape with rounded angles and uneven borders. Both the UV LCM and LAST sampled areas contain some coarse material. It is not clear if this is residual tissue or the result of ablated particulate being redeposited on the slide.

LAST sampling was more consistent and reproducible compared to UV LCM in all positions sampled. Even with the parameters that allowed the production of the $20 \mu \mathrm{m}$ ablation line shown 
in Figure 1, UV ablation displayed a high degree of inconsistency. Figure 2 shows that UV ablation with the LCM instrument was not reproducible even under these optimized conditions. It appears that UV ablation with the LCM instrument has a much stronger dependence on the characteristics of the biological surface sampled. The UV absorption of tissue is dominated by hemoglobin and melanin ${ }^{[47]}$ and, although the distribution of hemoglobin is homogeneous, the distribution of melanin is not ${ }^{[48]}$ and may have an effect on the ablation efficiency. In contrast, LAST, which relies on IR absorption, allows the complete ablation of material from all regions of the surface.

The protein concentration in the captured samples was measured using a Bradford colorimetric assay and bovine serum albumin as the protein standard. Figure 3 shows the results of the Bradford assay for UV and IR ablation. Compared to previous estimates of transfer efficiency, ${ }^{[27]}$ the recovery from this study was several fold higher. While there is little difference in protein material recovery among the LAST sampled regions, the UV LCM data are characterized by a higher variability. In the 3 out of 6 areas where UV LCM performed well, the recovery was higher for UV laser capture microdissection compared to IR ablation. The averaged coefficient of variation was 5\% for LAST whereas for UV LCM it was 55\%. LAST provides the reproducibility needed to create technical sampling replicates for downstream analytical evaluation.

The high variability in protein concentration measured for UV LCM does not appear to be correlated with the observed material removal in Figure 2. All positions in Figure 2 are similar in material removed by the UV laser, yet there is a wide variation in the total protein detected, as shown in Figure 3. This difference in protein recovery among the UV LCM samples may be due to the efficiency of ablation, capture, or extraction. The extraction step is often the major contributor to the overall variability of a mass spectrometry proteomic workflow: recently Piehowski and co-workers ${ }^{[49]}$ reported capture efficiency to be as high as $72 \%$ of the total variability. At the same time, it is clear that in the UV LCM ablated area the sample is not 
completely removed. In the IR LAST experiments, the material appears by visual inspection to be more completely and consistently removed.

Two consecutive sections mounted on the same slide were ablated and captured as described above. Three LAST/LCM pairs of samples in similar regions as in Figure 2 were obtained for the two sections. The material from the resulting 12 capture spots was subjected to enzymatic digestion for LC-MS analysis. Sample preparation for generating tryptic peptides was conducted using an ultracentrifugation unit with a mass cutoff of $10 \mathrm{kDa}$. Samples were processed in parallel and analyzed with the nanoLC ion trap mass spectrometer. The resulting MS/MS spectra were processed to generate peak lists that were used for peptides and proteins identification. Figure 4 shows base peak chromatograms for UV LCM and LAST from the samples obtain from the cerebellum region of one of the sections. The chromatograms obtained were characterized by signal intensity 3 orders of magnitudes higher than the corresponding blanks. An estimate of the number of cells ablated experiments was obtained by using an average cell diameter of $20 \mu \mathrm{m}$ (calculated using measurements reported in literature for both neurons and glial cells ${ }^{[50-52]}$ ), which resulted in a total of about 8,000 cells and a volume of $0.07 \mathrm{~mm}^{3}$. Shapiro and coworkers ${ }^{[53]}$ reported comparable results for base peak chromatograms (BPC) obtained from the LC-MS/MS analysis of 3,000 skin cells (keratinocytes). A comparison of the sampling variability between LCM and LAST at the chromatographic level was obtained by integrating BPCs from three sampled regions between 15 and 80 minutes. Coefficients of variations for the integrated intensities of the LAST samples were $15 \%, 20 \%$ and $18 \%$ for the striatum, midbrain and cerebellum regions, respectively. Coefficients of variations for the UV LCM samples were $35 \%$ and $20 \%$ and midbrain and cerebellum regions, respectively. Compared to the low variation measured at the protein level, LAST maintained a low variability for all the sampled regions. Peptide loadings from the UV LCM samples were more reproducible compared to the protein quantification data in the Bradford assay experiments, but they still resulted in high $\mathrm{CV}$ values. Moreover, none of the UV ablated samples displayed the high recovery (relative to LAST) shown for the assay in Figure 3. 
Figure 5 shows the number of proteins identified in the cerebellum and midbrain regions by LCMS. Data from each LC-MS run was searched against SwissProt database using PeptideShaker and multiple search engines. The similar number of matches and total number of proteins for cerebellum samples shown for LAST and LCM in Figure 5 is consistent with the high number of similar chromatographic peaks and intensities observed in the LAST and UV LCM samples shown in Figure 4. In the case of midbrain samples, UV LCM sampling showed a slightly lower material removal compared to Figure 2, which is consistent with the low intensity at the chromatographic level as well as a lower number of identified proteins compared to LAST. The evaluation of matches between each set of duplicates from Figure 5 revealed that more than half of the identified proteins were unique to the corresponding run. Technical analytical replicate runs are expected to improve the reproducibility as well as to increase the number of matches between samples processed on different sections. For the striatum region, LAST yielded a total of 88 for one section and 76 proteins for the other with a total of 127 with 37 proteins common to both sections. On the other hand, UV LCM ablation was not efficient no proteins were identified.

Figure 6 shows the results obtained from an analysis of proteins cellular localization for proteins in the cerebellum region. Protein ID lists obtained by combining the results from the two tissue sections were used as input. Both LAST and LCM were able to identify proteins belonging to several cellular compartments in addition to cytosol. A large number of proteins are membrane proteins, which suggests that organelles were lysed to various degrees and their protein material was made available for the enzymatic digestion. Wang and coworkers ${ }^{[54]}$ homogenized small slices of mouse brain with ultrasonication and trifluoroethanol based protein solubilization. After reduction, alkylation and trypsin digestion, fractions were isolated by strong cation exchange. Analysis of the 30 fractions LC-MS/MS produced similar distributions for most compartments to those shown in Figure 6. This suggests that our simplified protocol is capable of analyzing the entirety of the cell compartments even in the absence of sonication and detergents. 


\section{Conclusions}

This work compares the performance of LAST and UV LCM with regard to speed and efficiency for proteomics sampling. Spatially defined areas of $50 \mu \mathrm{m}$ thick tissue sections mounted on glass microscope slides yielded protein material for bottom-up mass spectrometry. IR laser ablation sampling was 300 times faster for ablation sampling of the sections and is more reproducible for removal of material from rat brain tissue sections. A CV of $5 \%$ was measured during total protein quantification assays of LAST samples. UV LCM had an inter-section CV of more than $50 \%$ and in two cases out of six it failed to recover sufficient material for LC-MS/MS analysis. Even in the absence of surfactants, our technology allowed for multi-compartment analysis of the sampled regions and low variability was demonstrated with measurements of the protein concentrations before enzymatic digestion as well as at the chromatographic level after LCMS/MS analysis of tryptic peptides with $20 \%$ as the highest CV of total peptides loaded on column. Future work is aimed at improving the protein identification using high-resolution mass spectrometry as well as comparison of the localization of identified proteins with conventional MALDI mass spectrometry imaging.

This article is protected by copyright. All rights reserved. 


\section{Acknowledgment}

This work was supported by the National Science Foundation (Grant No. CHE-1152106). The authors thank Dr. D. Baker (School of Veterinary Medicine, Louisiana State University, Baton Rouge, LA) for kindly providing rat brain and lung samples and Dr. H. Hale-Donze (Department of Biological Science, Louisiana State University, Baton Rouge, LA) for assistance with tissue microtome sectioning.
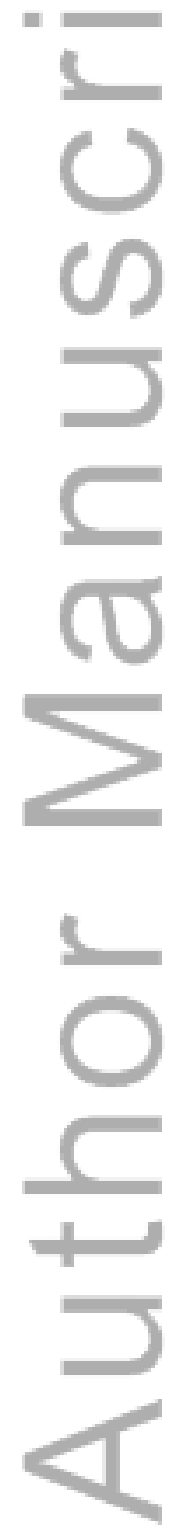


\section{References}

[1] T. Nilsson, M. Mann, R. Aebersold, J. R. Yates, 3rd, A. Bairoch, J. J. Bergeron. Mass spectrometry in high-throughput proteomics: ready for the big time, Nat Methods 2010, 7, 681.

[2] H. R. Jung, T. Sylvanne, K. M. Koistinen, K. Tarasov, D. Kauhanen, K. Ekroos. High throughput quantitative molecular lipidomics, Biochim Biophys Acta 2011, 1811, 925.

iri

[3] T. Fuhrer, N. Zamboni. High-throughput discovery metabolomics, Curr Opin Biotechnol 2015, 31, 73.

[4] M. P. Washburn, D. Wolters, J. R. Yates, 3rd. Large-scale analysis of the yeast proteome by multidimensional protein identification technology, Nat Biotechnol 2001, 19, 242.

[5] R. Aebersold, M. Mann. Mass spectrometry-based proteomics, Nature 2003, 422, 198.

[6] R. M. Caprioli. Imaging Mass Spectrometry: Enabling a New Age of Discovery in Biology and Medicine Through Molecular Microscopy, J. Am. Soc. Mass Spectrom. 2015, 26, 850.

[7] C. Giesen, H. A. O. Wang, D. Schapiro, N. Zivanovic, A. Jacobs, B. Hattendorf, P. J. Schuffler, D. Grolimund, J. M. Buhmann, S. Brandt, Z. Varga, P. J. Wild, D. Gunther, B. Bodenmillerthat. Highly multiplexed imaging of tumor tissues with subcellular resolution by mass cytometry, Nat. Methods 2014, 11, 417.

[8] C. W. Shields, C. D. Reyes, G. P. Lopez. Microfluidic cell sorting: a review of the advances in the separation of cells from debulking to rare cell isolation, Lab Chip 2015, 15, 1230.

[9] S. Di Palma, D. Stange, M. van de Wetering, H. Clevers, A. J. R. Heck, S. Mohammed. Highly -Sensitive Proteome Analysis of FACS-Sorted Adult Colon Stem Cells, J. Proteome Res. 2011, 10, 3814.

[10] M. R. Emmert-Buck, R. F. Bonner, P. D. Smith, R. F. Chuaqui, Z. P. Zhuang, S. R. Goldstein, R. A. Weiss, L. A. Liotta. Laser capture microdissection, Science 1996, 274, 998. 
[11] K. Schutze, G. Lahr. Identification of expressed genes by laser-mediated manipulation of single cells, Nat. Biotechnol. 1998, 16, 737.

[12] M. Vandewoestyne, K. Goossens, C. Burvenich, A. Van Soom, L. Peelman, D. Deforce. Laser capture microdissection: Should an ultraviolet or infrared laser be used?, Anal. Biochem. 2013, $439,88$.

[13] B. J. Xu. Combining laser capture microdissection and proteomics: methodologies and clinical = applications, Proteomics Clin. Appl. 2010, 4, 116.

[14] C. Stingl, F. G. I. van Vilsteren, C. Guzel, F. J. W. ten Kate, M. Visser, K. K. Krishnadath, J. J. Bergman, T. M. Luider. Reproducibility of Protein Identification of Selected Cell Types in Barrett's Esophagus Analyzed by Combining Laser-Capture Microdissection and Mass Spectrometry, J. Proteome Res. 2011, 10, 288.

[15] S. H. Chung, W. Y. Shen. Laser capture microdissection: from its principle to applications in research on neurodegeneration, Neural Regener. Res. 2015, 10, 897.

[16] L. Cheng, S. Zhang, D. Davidson, M. Kuhar, M. Wang, S. Williamson, D. Zhang, G. MacLennan, in Molecular Genetic Pathology (Eds.: L. Cheng, D. Y. Zhang, J. N. Eble), Springer New York, 2012, pp. 465.

[17] G. J. Van Berkel, V. Kertesz, K. A. Koeplinger, M. Vavrek, A. N. T. Kong. Liquid microjunction surface sampling probe electrospray mass spectrometry for detection of drugs and metabolites in thin tissue sections, J. Mass Spectrom. 2008, 43, 500.

[18] J. Sarsby, N. J. Martin, P. F. Lalor, J. Bunch, H. J. Cooper. Top-down and bottom-up identification of proteins by liquid extraction surface analysis mass spectrometry of healthy and diseased human liver tissue, J. Am. Soc. Mass Spectrom. 2014, 25, 1953.

[19] J. Quanico, J. Franck, C. Dauly, K. Strupat, J. Dupuy, R. Day, M. Salzet, I. Fournier, M. Wisztorski. Development of liquid microjunction extraction strategy for improving protein identification from tissue sections, J. Proteomics 2013, 79, 200. 
[20] V. Kertesz, G. J. Van Berkel. Sampling reliability, spatial resolution, spatial precision, and extraction efficiency in droplet-based liquid microjunction surface sampling, Rapid Commun. Mass Spectrom. 2014, 28, 1553.

[21] G. J. Van Berkel, V. Kertesz. Continuous-flow liquid microjunction surface sampling probe - connected on-line with high-performance liquid chromatography/mass spectrometry for spatially resolved analysis of small molecules and proteins, Rapid. Commun. Mass Spectrom. 2013, 27, 1329.

[22] J. Laskin, B. S. Heath, P. J. Roach, L. Cazares, O. J. Semmes. Tissue Imaging Using Nanospray Desorption Electrospray Ionization Mass Spectrometry, Anal. Chem. 2012, 84, 141.

[23] M. Lorenz, O. S. Ovchinnikova, V. Kertesz, G. J. Van Berkel. Laser microdissection and atmospheric pressure chemical ionization mass spectrometry coupled for multimodal imaging, Rapid Commun. Mass Spectrom. 2013, 27, 1429.

[24] S. G. Park, K. K. Murray. Infrared laser ablation sample transfer for MALDI and electrospray, J. Am. Soc. Mass Spectrom. 2011, 22, 1352.

[25] S. G. Park, K. K. Murray. Laser ablation sample transfer for mass spectrometry imaging, Methods Mol. Biol. 2015, 1203, 129.

[26] S.-G. Park, Murray, Kermit K. Infrared Laser Ablation Sample Transfer for MALDI Imaging, Anal. Chem. 2012, 84, 3240.

[27] S. G. Park, K. K. Murray. Infrared laser ablation sample transfer for on-line liquid chromatography electrospray ionization mass spectrometry, J. Mass Spectrom. 2012, 47, 1322.

[28] S. G. Park, K. K. Murray. Ambient laser ablation sampling for capillary electrophoresis mass spectrometry, Rapid Commun. Mass Spectrom. 2013, 27, 1673.

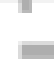

[29] M. Kwiatkowski, M. Wurlitzer, M. Omidi, L. Ren, S. Kruber, R. Nimer, W. D. Robertson, A. Horst, R. J. Miller, H. Schluter. Ultrafast extraction of proteins from tissues using desorption by impulsive vibrational excitation, Angew. Chem. Int. Ed. Engl. 2015, 54, 285. 
[30] J. T. O'Brien, E. R. Williams, H. Y. Holman. Ambient infrared laser ablation mass spectrometry (AIRLAB-MS) of live plant tissue with plume capture by continuous flow solvent probe, Anal Chem 2015, 87, 2631.

[31] R. S. Jacobson, R. L. Thurston, B. Shrestha, A. Vertes. In Situ Analysis of Small Populations of -Adherent Mammalian Cells Using Laser Ablation Electrospray Ionization Mass Spectrometry in Transmission Geometry, Anal Chem 2015, 87, 12130.

[32] "= S.-G. Park, K. K. Murray. Infrared laser ablation sample transfer for MALDI and electrospray, J. Am. Soc. Mass Spectrom. 2011, 22, 1352.

[33] K. L. Caldwell, D. R. McGarity, K. K. Murray. Matrix-assisted laser desorption/ionization with a tunable mid-infrared optical parametric oscillator, J. Mass Spectrom. 1997, 32, 1374.

[34] M. W. Little, J. Laboy, K. K. Murray. Wavelength dependence of soft infrared laser desorption and ionization, Journal of Physical Chemistry C 2007, 111, 1412.

[35] J. R. Wisniewski, A. Zougman, N. Nagaraj, M. Mann. Universal sample preparation method for proteome analysis, Nat. Methods 2009, 6, 359.

[36] M. Vaudel, H. Barsnes, F. S. Berven, A. Sickmann, L. Martens. SearchGUI: An open-source graphical user interface for simultaneous OMSSA and X!Tandem searches, Proteomics 2011, 11, 996.

[37] R. Craig, R. C. Beavis. TANDEM: matching proteins with tandem mass spectra, Bioinformatics 2004, 20, 1466.

[38] S. Kim, P. A. Pevzner. MS-GF+ makes progress towards a universal database search tool for proteomics, Nat. Commun. 2014, 5, 5277.

[39] V. Dorfer, P. Pichler, T. Stranzl, J. Stadlmann, T. Taus, S. Winkler, K. Mechtler. MS Amanda, a universal identification algorithm optimized for high accuracy tandem mass spectra, J. Proteome Res. 2014, 13, 3679. 
[40] D. L. Tabb, C. G. Fernando, M. C. Chambers. MyriMatch: highly accurate tandem mass spectral peptide identification by multivariate hypergeometric analysis, J. Proteome. Res. 2007, 6, 654.

[41] J. K. Eng, T. A. Jahan, M. R. Hoopmann. Comet: an open-source MS/MS sequence database search tool, Proteomics 2013, 13, 22.

[42] L. Y. Geer, S. P. Markey, J. A. Kowalak, L. Wagner, M. Xu, D. M. Maynard, X. Yang, W. Shi, S. H. Bryant. Open mass spectrometry search algorithm, J. Proteome Res. 2004, 3, 958.

$=$

[43] M. Vaudel, J. M. Burkhart, R. P. Zahedi, E. Oveland, F. S. Berven, A. Sickmann, L. Martens, H. Barsnes. PeptideShaker enables reanalysis of MS-derived proteomics data sets, Nat. Biotechnol. 2015, 33, 22.

[44] C. UniProt. UniProt: a hub for protein information, Nucleic Acids Res. 2015, 43, D204.

[45] T. Pluskal, S. Castillo, A. Villar-Briones, M. Oresic. MZmine 2: modular framework for processing, visualizing, and analyzing mass spectrometry-based molecular profile data, BMC Bioinform. 2010, 11, 395.

[46] C. Blind, A. Koepenik, M. Pacyna-Gengelbach, G. Fernahl, N. Deutschmann, M. Dietel, V. Krenn, I. Petersen. Antigenicity testing by immunohistochemistry after tissue oxidation, J. Clin. Pathol. $2008,61,79$.

[47] A. Vogel, V. Venugopalan. Mechanisms of pulsed laser ablation of biological tissues, Chemical reviews 2003, 103, 577.

[48] B. Bogerts. A brainstem atlas of catecholaminergic neurons in man, using melanin as a natural marker, J Comp Neurol 1981, 197, 63.

[49] P. D. Piehowski, V. A. Petyuk, D. J. Orton, F. Xie, R. J. Moore, M. Ramirez-Restrepo, A. Engel, A. P. Lieberman, R. L. Albin, D. G. Camp, R. D. Smith, A. J. Myers. Sources of technical variability in quantitative LC-MS proteomics: human brain tissue sample analysis, J. Proteome Res. 2013, 12, 2128. 
[50] P. Mensah, S. Deadwyler. The caudate nucleus of the rat: cell types and the demonstration of a commissural system, J. Anat. 1974, 117, 281.

[51] M. Davanlou, D. F. Smith. Unbiased stereological estimation of different cell types in rat cerebral cortex, Image Anal. Stereol. 2004, 23, 11. 1

[52] S. E. Poduslo, in Research Methods in Neurochemistry (Eds.: N. Marks, R. Rodnight), Springer US, 1981, pp. 113.

$$
=
$$

[53] J. P. Shapiro, S. Biswas, A. S. Merchant, A. Satoskar, C. Taslim, S. L. Lin, B. H. Rovin, C. K. Sen, S. Roy, M. A. Freitas. A quantitative proteomic workflow for characterization of frozen clinical biopsies: Laser capture microdissection coupled with label-free mass spectrometry, $J$. Proteomics 2012, 77, 433.

[54] H. X. Wang, W. J. Qian, M. H. Chin, V. A. Petyuk, R. C. Barry, T. Liu, M. A. Gritsenko, H. M. "Mottaz, R. J. Moore, D. G. Camp, A. H. Khan, D. J. Smith, R. D. Smith. Characterization of the mouse brain proteome using global proteomic analysis complemented with cysteinyl-peptide enrichment, J. Proteome Res. 2006, 5, 361.

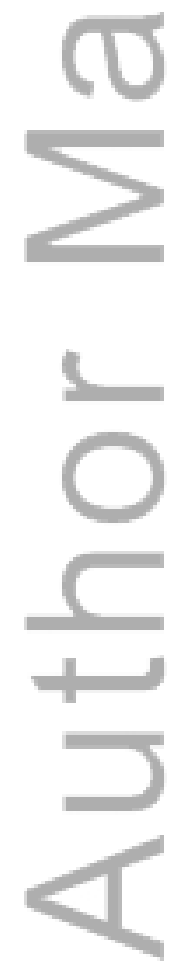




\section{List of Figures}
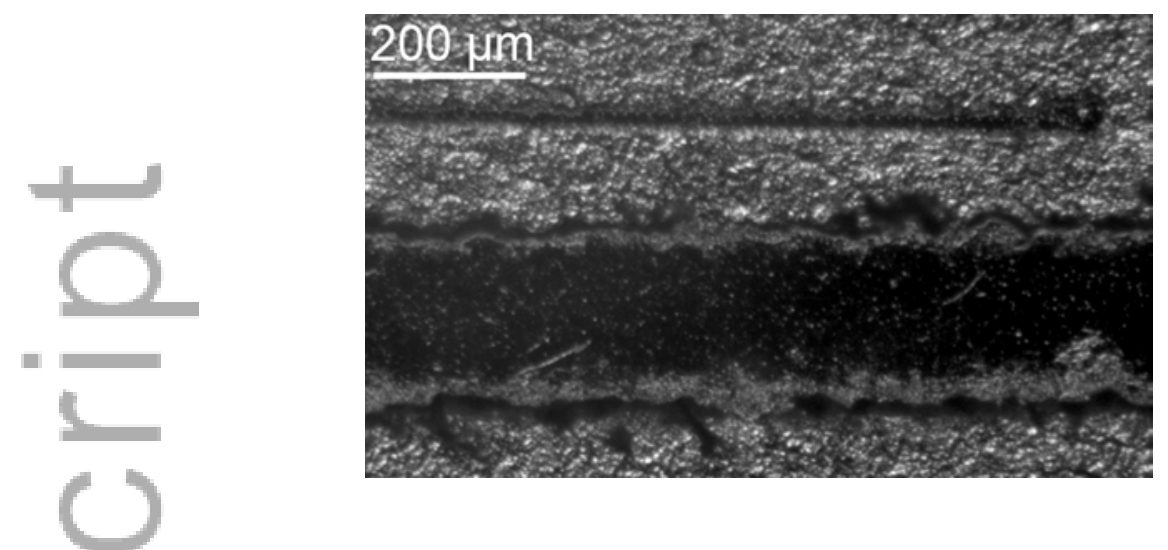

Figure 1. Optimization of ablation of rat brain tissue sections with IR optical parametric oscillator laser and the $\mathrm{N}_{2}$ laser of the LCM instrumentation. The IR laser produced a focused spot of about $200 \mu \mathrm{m}$ in diameter. The LCM UV laser allowed for spot 10 times smaller, with a diameter of about $20 \mu \mathrm{m}$. IR ablation could be conducted at translation speed of $1 \mathrm{~mm} / \mathrm{s}$ and repetition rates of $20 \mathrm{~Hz}(\approx 5$ shots over a $200 \times 200$ square $\mu \mathrm{m}$ spot $)$. LCM experiments required accumulation of 100 pulses per spot at $100 \mathrm{~Hz}$ and maximum energy in order to achieve material detachment. This was achieved with the laser pulse mode where the laser was positioned on one spot of the raster and moved after 1 second to the next spot, $15 \mu \mathrm{m}$ away. 

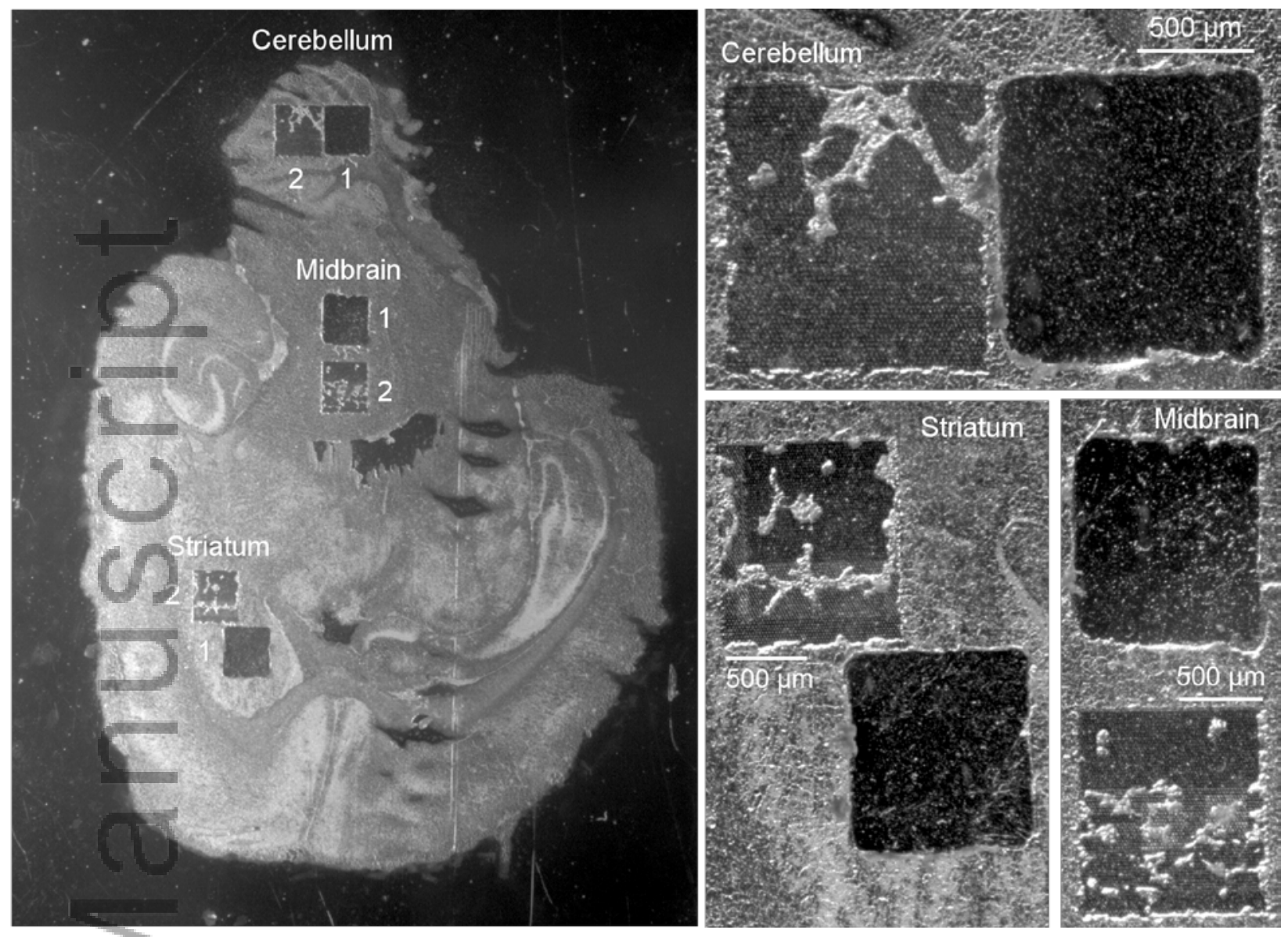

Figure 2. Bright field microscope images of the sampled area with LAST (labelled "1") and UV LCM (labelled "2"). Three regions were selected and 2 rectangles of $1.2 \times 1.1 \mathrm{~mm}$ were sampled for each of them with either LAST or UV LCM. A consecutive section mounted on the same microscope slide was processed in parallel selecting the same three regions. Panels on the right are zoomed in images of the whole section on the left.

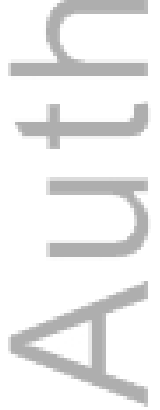



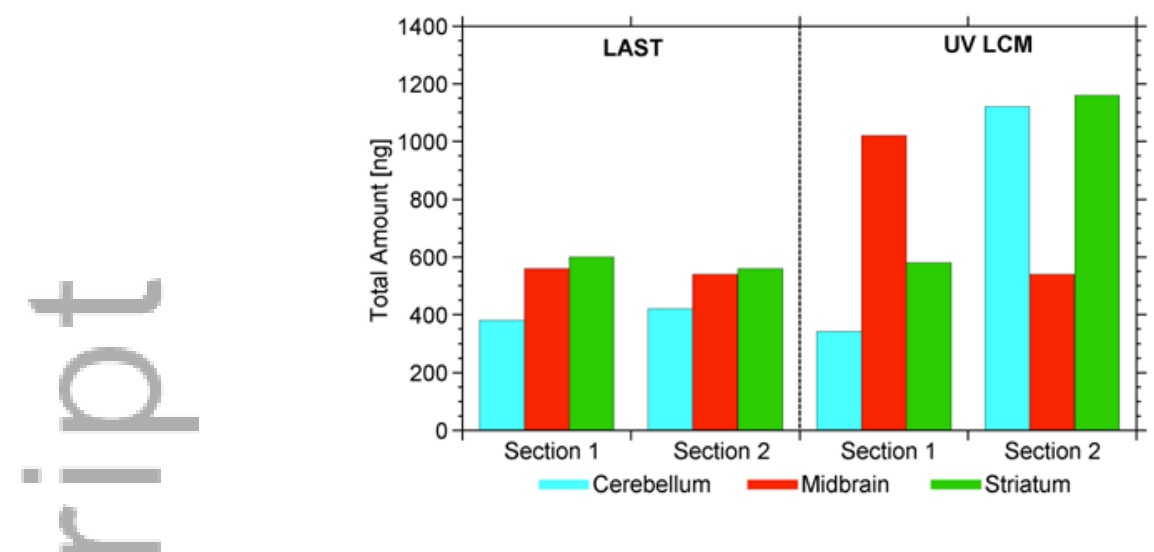

Figure 3. Protein concentrations from UV LCM and LAST sampled regions. Section 1 is the section showed in Figure 2. Cerebellum, midbrain and striatum are the same regions showed in Figure 2. Quantification was performed with Bradford colorimetric assay following the manufacturer protocol and using bovine serum albumin as standard. 

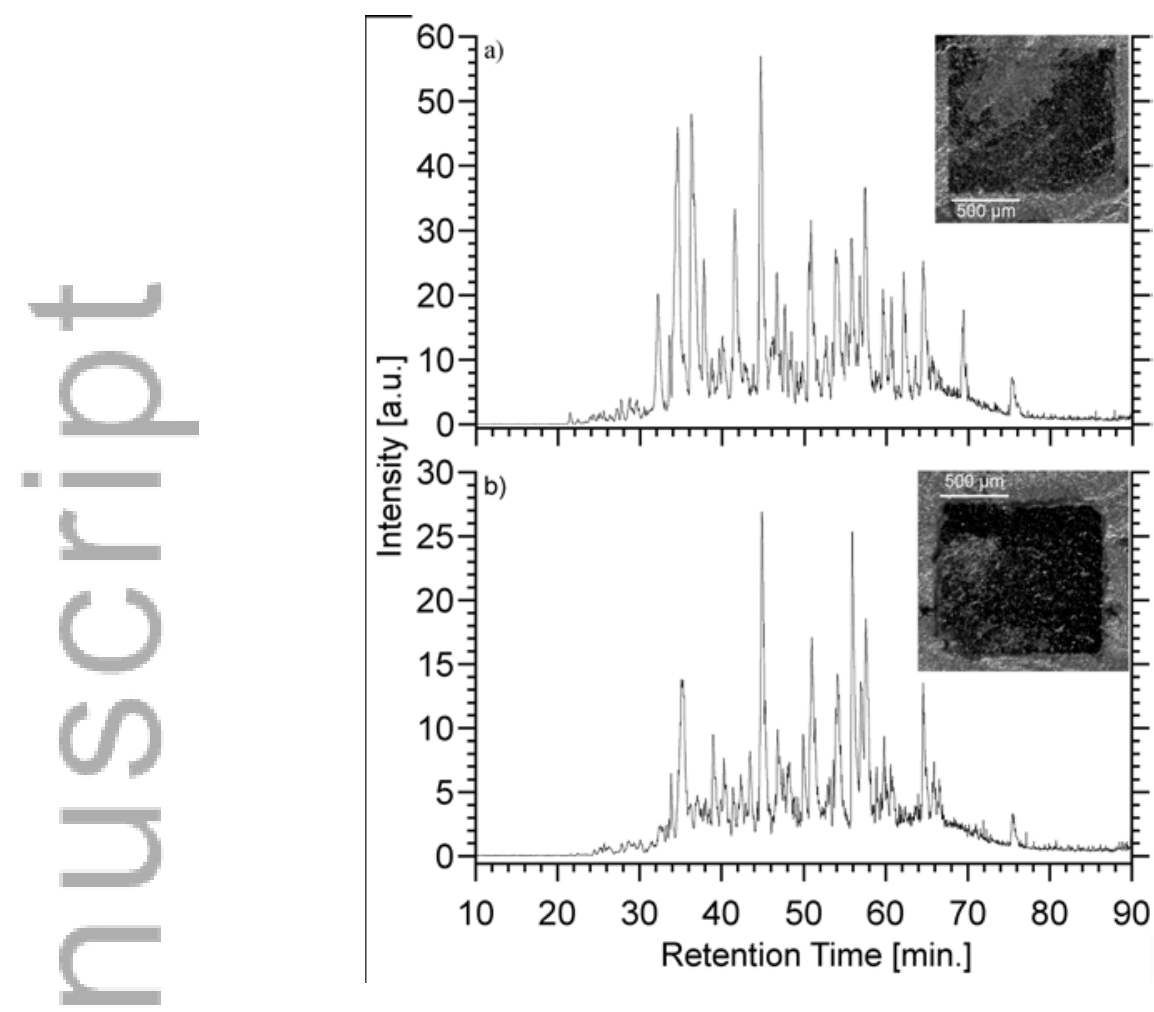

Figure 4. Base peak chromatograms of tryptic peptide mixtures obtained from position D on section 3: a) chromatogram from LCM sampled area; b) chromatogram of LAST sampled area. Insets show the bright field images of the respective ablated area. Intensities were divided by $10^{7}$.

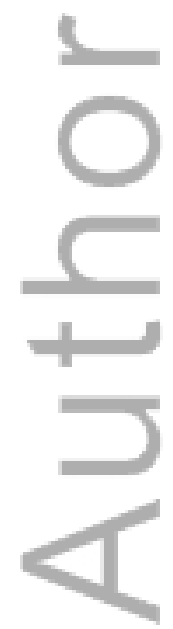




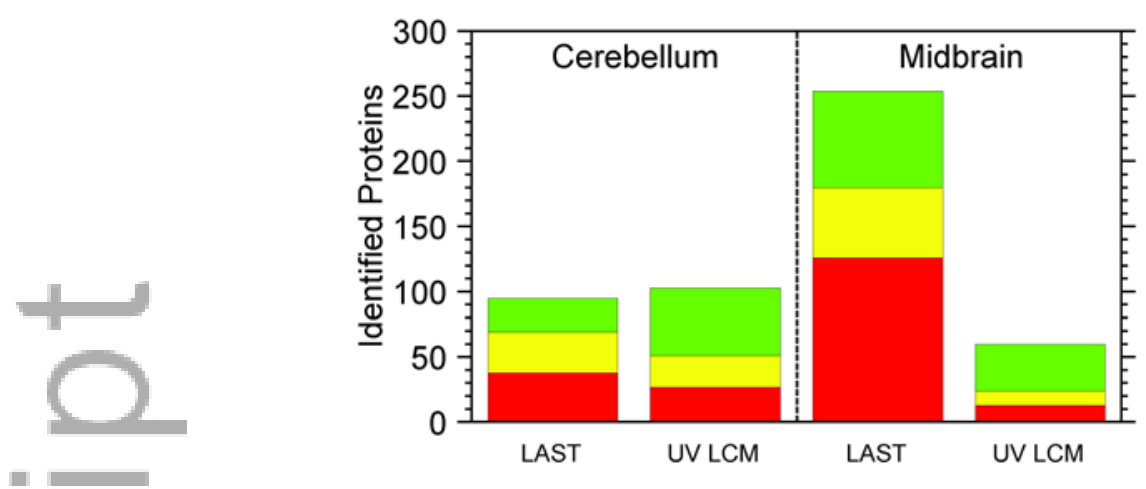

Figure 5. Number of identified proteins from database search of LC-MS/MS runs from cerebellum and midbrain regions on two consecutive rat tissue sections. In each region, two adjacent positions were sampled with UV LCM and LAST respectively. Red and green blocks represent the protein unique to each section while yellow blocks represent the protein identified in both sections.

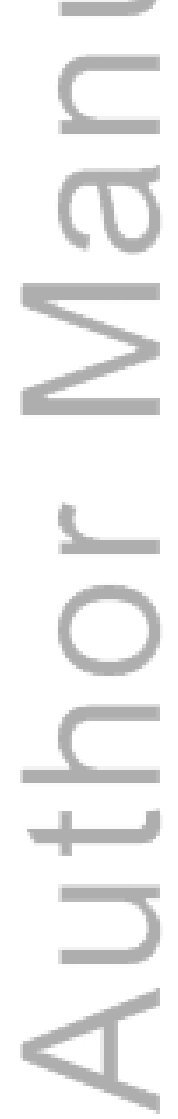




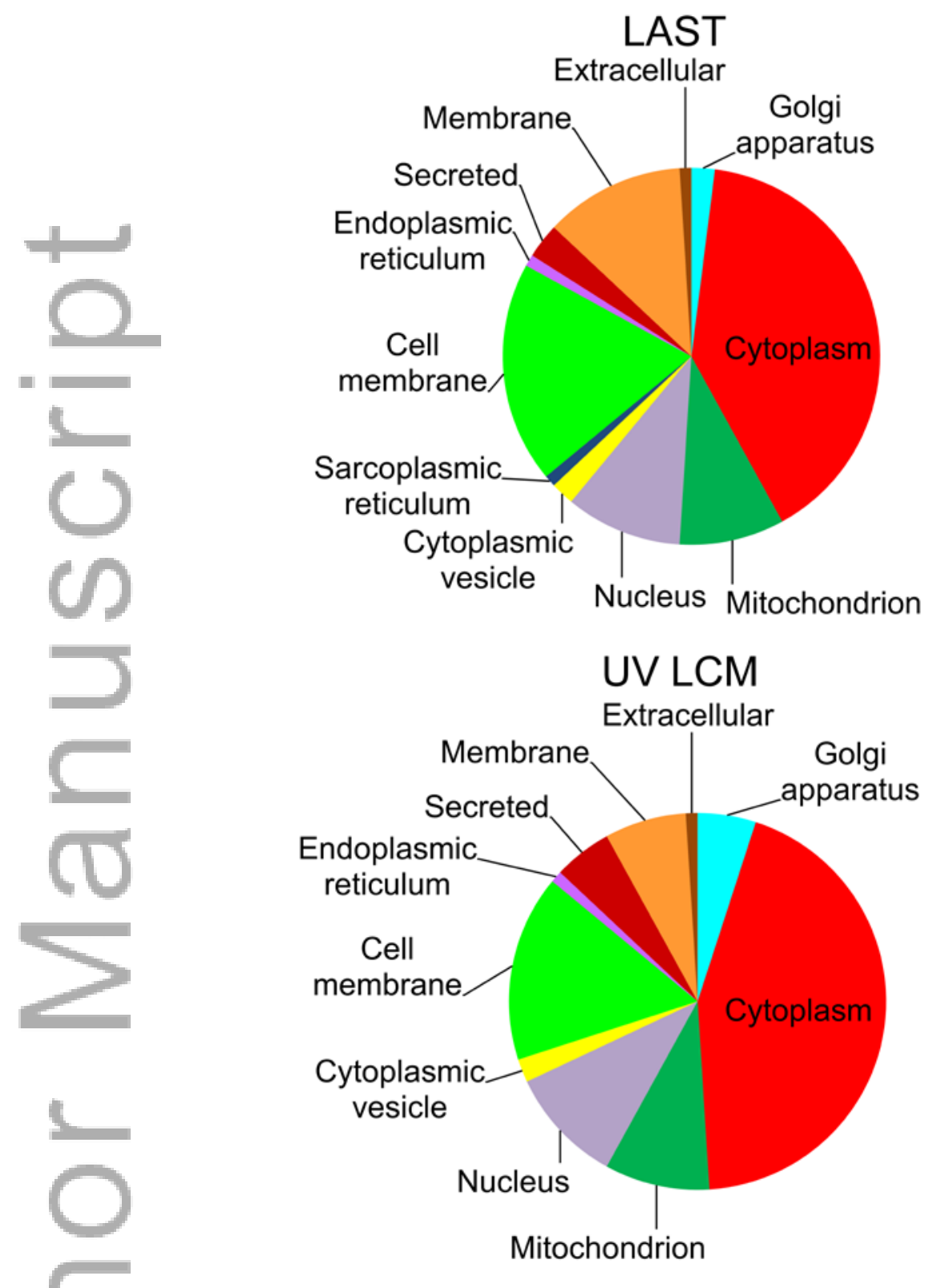

Figure 6. Gene ontology derived localization of proteins found in the cerebellum area for LAST and UV LCM sampling. Protein IDs from both sections have been combined in a single list that was searched against UniProtKB (release 2015/08) database. Searches have been conducted using the localization keywords reported in the labels. 

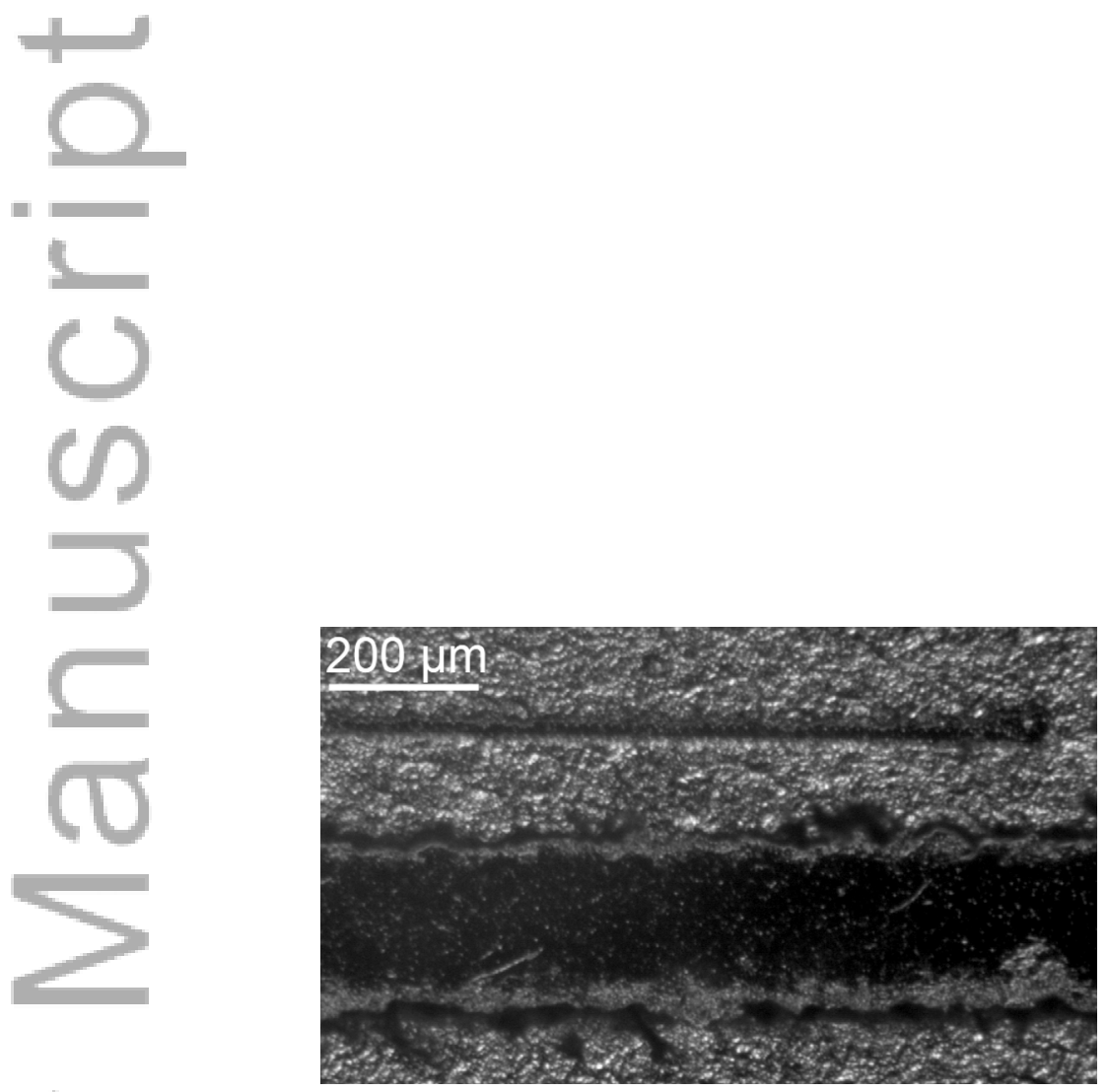

JMS_3744_F1 .tif

This article is protected by copyright. All rights reserved. 


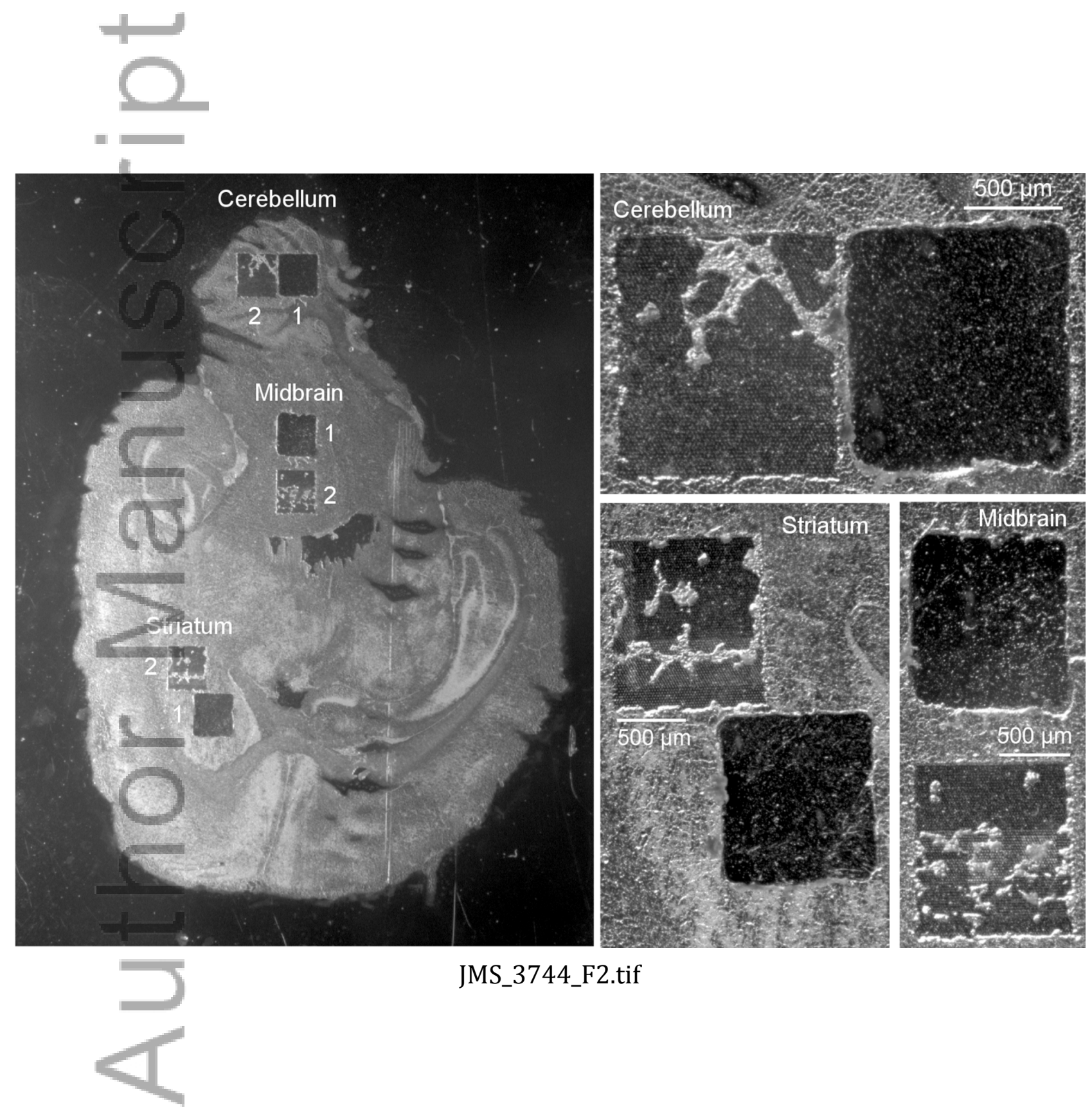

This article is protected by copyright. All rights reserved. 

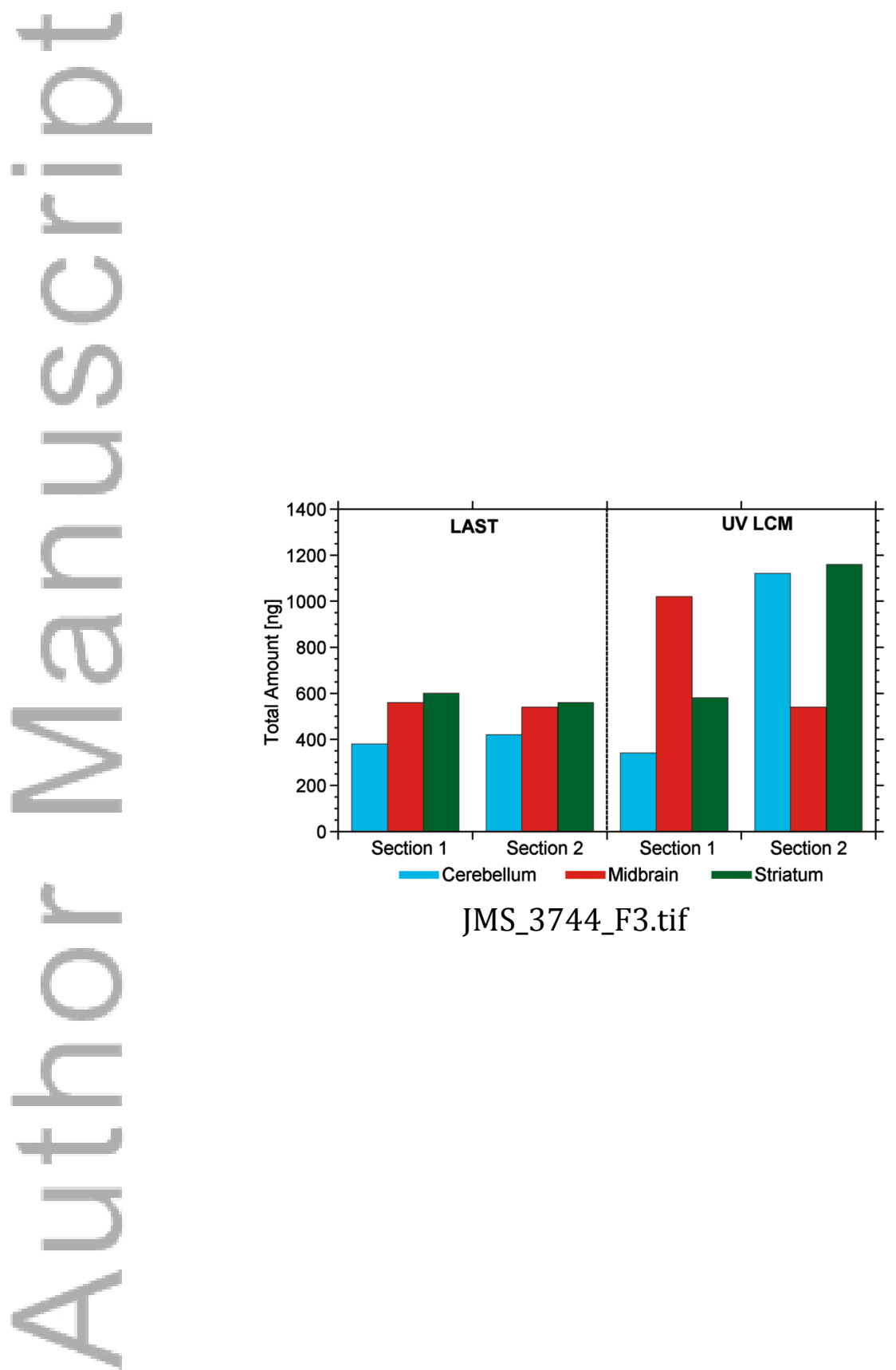

This article is protected by copyright. All rights reserved. 

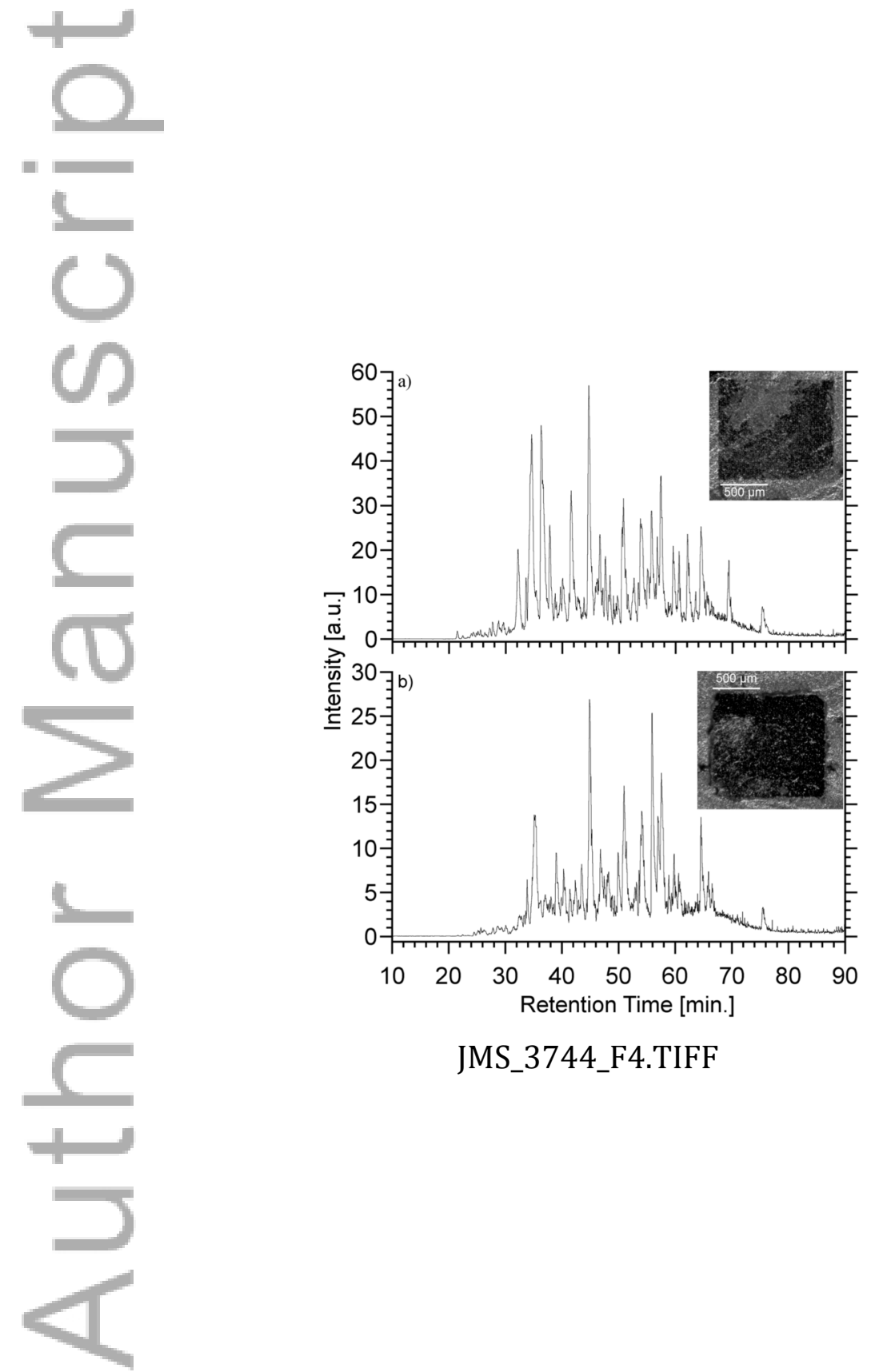

JMS_3744_F4.TIFF

This article is protected by copyright. All rights reserved. 

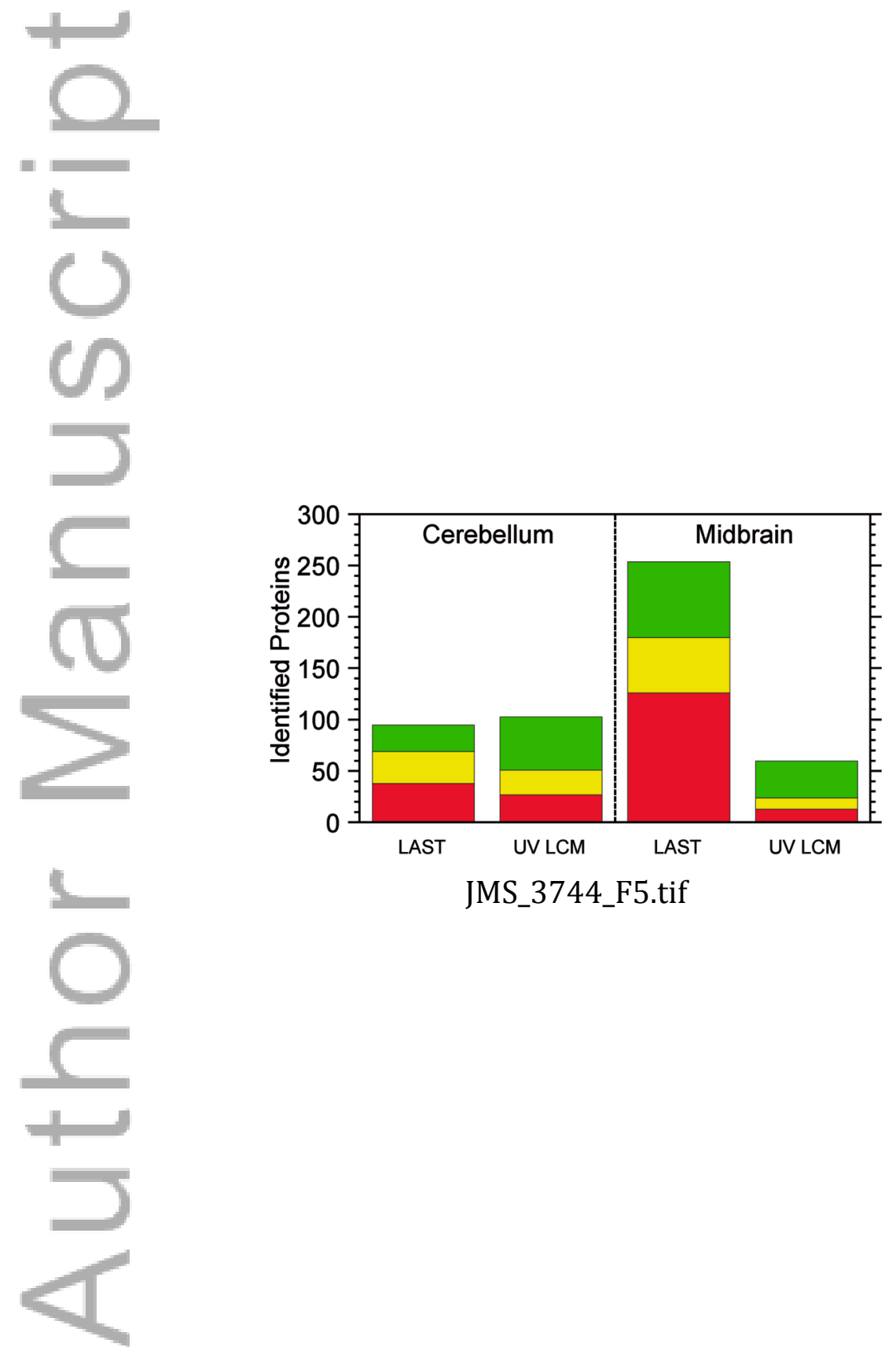

This article is protected by copyright. All rights reserved. 

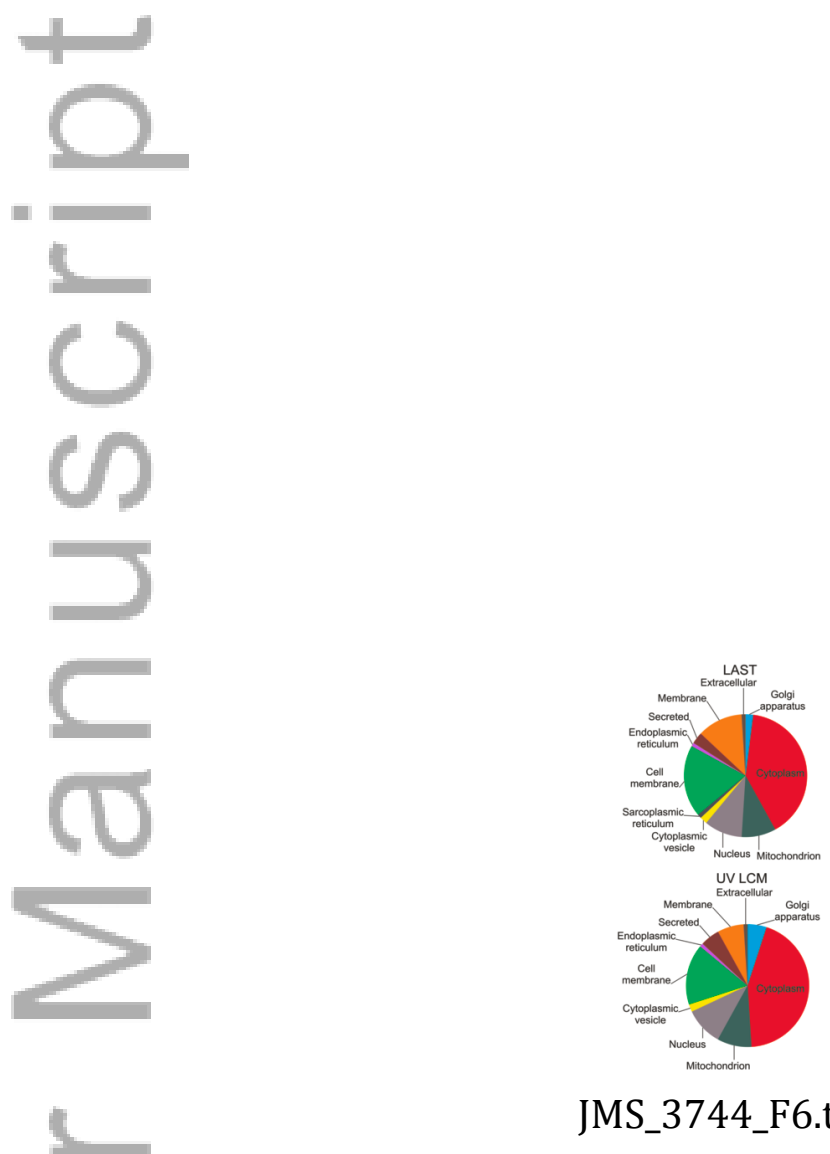

JMS_3744_F6.tif

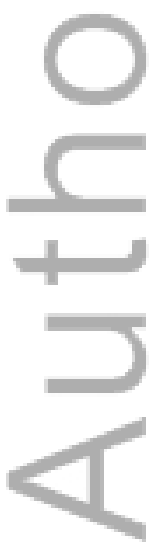

This article is protected by copyright. All rights reserved. 